\title{
Laboreal
}

Volume $3 \mathrm{~N}^{\circ} 1$ | 2007

Varia

\section{O que faz o medo de aprender na zona de desenvolvimento proximal?}

¿Qué hace el miedo de aprender en la zona de desarrollo proximal?

Que fait la peur d'apprendre dans la zone prochaine de développement?

What is fear of learning doing in the zone of proximal development?

\section{Marta Santos e Marianne Lacomblez}

\section{(2) OpenEdition}

\section{Journals}

\section{Edição electrónica}

URL: http://journals.openedition.org/laboreal/12729

DOI: $10.4000 /$ laboreal. 12729

ISSN: 1646-5237

\section{Editora}

Universidade do Porto

\section{Refêrencia eletrónica}

Marta Santos e Marianne Lacomblez, « O que faz o medo de aprender na zona de desenvolvimento proximal ? », Laboreal [Online], Volume $3 \mathrm{~N}^{0} 1$ | 2007, posto online no dia 01 julho 2007, consultado o 10 outubro 2019. URL : http://journals.openedition.org/laboreal/12729; DOI : 10.4000/laboreal.12729

Este documento foi criado de forma automática no dia 10 outubro 2019.

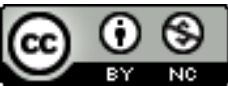

Laboreal está licenciado com uma Licença Creative Commons - Atribuição-NãoComercial 4.0 Internacional. 


\title{
O que faz o medo de aprender na zona de desenvolvimento proximal ?
}

\author{
¿Qué hace el miedo de aprender en la zona de desarrollo proximal? \\ Que fait la peur d'apprendre dans la zone prochaine de développement? \\ What is fear of learning doing in the zone of proximal development?
}

Marta Santos e Marianne Lacomblez

\section{Zona de desenvolvimento proximal}

1 O conceito de Zona de Desenvolvimento Proximal de Vygotski (1934/1997) é, possivelmente, um dos conceitos da sua obra que maior divulgação acabou por ter. Com efeito, são bastantes os contextos de aprendizagem que passaram a recorrer a este conceito como forma de justificar o que deveria ser aprendido e o que é que já se está em condições de aprender.

De acordo com Vygotski (1934/1997), não é suficiente determinar aquilo que a criança já é capaz de fazer sozinha, de modo autónomo - que corresponde ainda a uma forma recorrente de avaliação do seu nível de desenvolvimento. É preciso, de igual forma, conhecer aquilo que ainda está em estado de maturação e que equivale àquilo que a criança consegue realizar com a ajuda de um adulto. Ao educador/formador cabe o papel de criar situações de conflito, de contradição, tornando-se o espaço que medeia entre aquilo que a criança faz sozinha (desenvolvimento já alcançado) e o que faz com ajuda nestas condições de conflito positivo (desenvolvimento futuro) o que Vygotski decidiu designar de zona de desenvolvimento proximal (Schneuwly, 1994). Aquilo que hoje a criança consegue realizar em colaboração com o outro nestas condições é aquilo que possivelmente ela vai ser capaz de realizar no futuro de forma autónoma.

3 Mas se é inegável a utilidade de um conceito como este para ajudar a definir o que se pode ensinar e o que se está em condições de aprender, não é invulgar que a sua 
utilização seja inserida no quadro de abordagens que não receiam misturar recursos teóricos e metodológicos e que acabam por se expor a contradições flagrantes. Assim, falar ao mesmo tempo, para justificar a mesma intervenção, de zona de desenvolvimento proximal e de estruturas de desenvolvimento inatas (na linha da obra de Piaget), significa, no mínimo, fazer coabitar posturas teóricas muito distintas.

Vale pois a pena, situar uma vez mais este conceito na abordagem de Vygotski, mesmo sem objectivos de exaustividade, já que pretendemos utilizá-lo para uma leitura de um caso prático de formação profissional.

\subsection{Ferramentas e signos}

5 O conceito de zona de desenvolvimento proximal enquadra-se no seio da teoria histórico-cultural onde, contrariamente às teorias psicológicas dominantes no início do século XX, não se pressupõe a existência de mecanismos inerentes à condição humana, não se considera a existência de uma natureza inata que, por si só, fosse capaz de conferir as características especificamente humanas. Para Vygotski, os processos psicológicos superiores (como por exemplo a abstracção, a generalização, a memória selectiva, a atenção deliberada,...), que caracterizam e diferenciam o Homem dos outros animais, só são possíveis pela utilização da linguagem em situações históricas e culturais que favoreçam/permitam o seu desenvolvimento.

6 A linguagem é considerada, então, como um instrumento privilegiado, na medida em que, por um lado, permite a partilha das representações vigentes numa sociedade determinada histórica e culturalmente, bem como, a conservação e passagem às gerações seguintes, dos conhecimentos adquiridos num determinado momento. É através da mediação da linguagem que se torna possível a reorganização dos processos psicológicos para as suas formas superiores, especificamente humanas.

7 Assim, Vygotski para além de se referir às relações mediadas por instrumentos e ferramentas (como sendo as que permitem a acção do homem sobre a natureza), acrescenta que a acção do homem sobre si próprio e sobre os outros é mediada por sistemas de signos (linguagem, sistema de números, mapas, esquemas,...) dos quais se destacam os signos verbais. Aliás, na opinião de Rochex (1997), a originalidade de Vygotski consiste justamente no alargamento conceptual da noção de ferramenta para a de conduta semiótica.

8 O que distingue, em Vygotski, os instrumentos dos signos é o facto de estes últimos se situarem no campo psicológico : ambos são meios auxiliares, intermédios, mediadores na resolução de determinadas situações. No caso dos signos, são psicológicas, como ter que lembrar, comparar, relatar, escolher qualquer coisa.

9 Assim podemos dizer que os instrumentos estão para o trabalho como os signos estão para a actividade psicológica e ambos podem ser "incluídos dentro do conceito mais geral de actividade indirecta (mediada)" (Vygotski, 1931/1998, p. 71, tradução livre). Mas podemos ir mais longe, já que se em comum têm o facto de pertencerem à categoria de actividades mediadas, segundo Vygotski, eles correspondem justamente a linhas divergentes desta mesma actividade pela forma como orientam o comportamento humano :

10 A função do instrumento é servir como um condutor da influência humana sobre o objecto da actividade; ele é orientado externamente; deve necessariamente levar a 
mudanças nos objectos. (...) O signo, por outro lado, não modifica em nada o objecto da operação psicológica. Constitui um meio da actividade interna dirigido para o controle do próprio indivíduo ; o signo é orientado internamente. (Vygotski, 1931/1998, p. 72 e 73, tradução livre)

11 Ora, para o nosso objectivo neste trabalho, interessa reter, desde já, que é a apropriação destas ferramentas e instrumentos, enquanto "meios de contacto com o mundo exterior e consigo próprio (com a sua própria consciência)" (Bronckart, 1985, p. 14, tradução livre) que, em situações de interacção comunicacional, de "cooperações assimétricas » (Rochex, 1997, p. 128), possibilita o desenvolvimento.

\subsection{0 estatuto dos conceitos}

\subsubsection{A formação dos “ verdadeiros » conceitos}

12 Isto significa, então, que é necessário, numa situação de aprendizagem, que exista alguém (um adulto, um professor) que, pela mediação da linguagem e outras ferramentas, possa ensinar os conceitos que estão em condições de ser aprendidos. Duas questões portanto : uma relativa aos conceitos e outra às condições...

13 Debrucemo-nos sobre ambas: como, e de que forma, é que se formam os “verdadeiros » conceitos, aqueles que devem ser aprendidos numa situação formal de aprendizagem?

14 Através da realização de um conjunto de experiências, Vygotski, acaba por concluir que "o desenvolvimento dos processos que finalmente resultam na formação de conceitos começa na fase mais precoce da infância, mas as funções intelectuais que, numa combinação específica, formam a base psicológica do processo da formação de conceitos amadurecem e desenvolvem-se somente na puberdade" (Vygotski, 1934/1997, p. 204 e 205, tradução livre).

15 De facto, para o autor, a formação de “verdadeiros" conceitos só é possível na adolescência, porque implica o desenvolvimento de funções intelectuais superiores como a atenção deliberada, memória lógica, abstracção, capacidade para comparar e diferenciar. Com efeito, os "verdadeiros" conceitos, as formas superiores, que correspondem ao pensamento conceptual, implicam não só o acto de generalização (também presente em formas menos evoluídas como nos pseudo-conceitos), "mas também a sua diferenciação, a sua abstracção e o seu isolamento e a capacidade de examinar os seus elementos de forma diferenciada, abstractos, fora da ligação concreta e empírica nos quais eles são fornecidos." (Vygotski, 1934/1997, p. 252, tradução livre).

Para que este processo possa ocorrer, Vygotski salienta, uma vez mais, a importância da mediação da linguagem :

0 processo de formação de conceitos não é redutível às associações, à atenção, à representação, ao julgamento, às tendências determinantes, se bem que todas estas funções participem inegavelmente nesta síntese complexa que representa, de facto, este processo. 0 elemento central é aqui, como mostra o estudo, a utilização funcional do signo ou da palavra, como o meio que permite ao adolescente de submeter ao seu poder as suas próprias operações psíquicas, de gerir o percurso dos seus próprios processos psíquicos e de orientar a sua actividade em direcção à resolução do problema com o qual é confrontado. (Vygotski, 1934/1997, p. 206 e 207, tradução livre). 
17 No seguimento deste excerto podemos constatar também que um outro aspecto que vai potenciar a construção do pensamento conceptual é a confrontação com situaçõesproblema: embora o pensamento conceptual não possa ser considerado como o resultado da confrontação dos adolescentes com uma situação problemática, todavia, o ingresso no mundo cultural e profissional dos adultos é, assumido pelo autor, como um factor preponderante para o seu desenvolvimento. Vygotski considera que quando o meio envolvente não proporciona novas tarefas, exigências e desafios, o raciocínio dos adolescentes não conseguirá atingir os estádios mais elevados ou só os alcançará com um grande atraso.

\subsubsection{Conceitos científicos e conceitos espontâneos}

Quando a preocupação é ensinar os “ verdadeiros » conceitos, os que são mediados pela linguagem e que permitem resolver os problemas com que nos defrontamos, é útil atentar à distinção proposta pelo autor entre conceitos científicos e conceitos espontâneos.

Desde já podemos dizer que, de acordo com o proposto por Vygotski, os conceitos espontâneos são aqueles que são adquiridos através da experiência pessoal enquanto que os conceitos científicos são constituídos em situações estruturadas de aprendizagem. Isto significa que os dois tipos de conceitos se desenvolvem sob condições internas e externas completamente diferentes. Isto é, os motivos que levam à sua formação não são os mesmos e a forma como a " mente » reage quando se defronta com problemas novos em situação escolar ou entregue aos seus próprios recursos, também não é a mesma.

Relativamente aos conceitos científicos, a aprendizagem escolar, ensina, muitas vezes, coisas que a criança não pode experenciar de forma directa e pessoal, pelo que acaba por induzir, de acordo com Vygotski, uma percepção generalizante que assume um papel decisivo na tomada de consciência, por parte da criança, dos seus próprios processos mentais. Por outro lado, pelo facto dos conceitos científicos aprendidos na escola, terem a relação com o objecto mediada por um outro conceito científico, a criança começa, desde logo, a estabelecer relações (hierárquicas) entre conceitos.

21 A aprendizagem de um conceito científico começa normalmente com a sua definição verbal, aplicando-a, posteriormente, em situações não-espontâneas. Desta forma, o desenvolvimento dos conceitos científicos é descendente (do abstracto para um nível mais concreto), enquanto que no caso dos conceitos espontâneos assiste-se ao processo inverso, ascendente : do particular, mais concreto, para a situação geral, mais abstracta. Esta questão relaciona-se, naturalmente, com a forma como os dois tipos de conceitos são adquiridos: enquanto que o conceito espontâneo está, como dissemos, mais relacionado com a vivência de uma situação concreta, o conceito científico é aprendido sempre num contexto mediado face ao seu objecto (mediado por outros conceitos e pelo próprio papel do professor). Para poder compreender de que forma os conceitos científicos são aprendidos, Vygotski conduziu novas experiências que procuravam analisar a relação entre a aprendizagem e o desenvolvimento. Entre os seus principais resultados, destacamos os seguintes :

- relativamente ao nível de desenvolvimento das funções psicológicas necessárias para a aprendizagem das matérias escolares básicas, Vygotski conclui que este desenvolvimento não precede essa aprendizagem, mas desenvolve-se numa interacção contínua com as suas 
contribuições ; isto é, para iniciar o percurso escolar a criança não necessita de já possuir um determinado nível de desenvolvimento. Pelo contrário, serão as aprendizagens que fará na escola, conjuntamente com o seu desenvolvimento actual, que possibilitarão novos desenvolvimentos.

- aliás, no que se relaciona com a relação temporal entre os processos de aprendizagem e o desenvolvimento das funções psicológicas correspondentes, Vygotski considera que o desenvolvimento não coincide com a aprendizagem escolar, sendo que, normalmente, a aprendizagem precede o desenvolvimento.

- uma terceira série de investigações foi conduzida como objectivo de analisar o processo de transferência das aprendizagens. Vygotski considera que as disciplinas escolares básicas (leitura e escrita, aritmética e ciências naturais) actuam como uma disciplina formal, cada uma facilitando a aprendizagem das outras, sobretudo por partilharem como base comum a tomada de consciência e o domínio deliberado.

- finalmente, a quarta série de investigações (responsável pelo formulação do conceito de zona de desenvolvimento proximal) debruçou-se sobre a forma como pode ser avaliado o nível de desenvolvimento mental das crianças. Assim, tal como referimos anteriormente, Vygotski constata que a forma como normalmente se avalia a criança só tem em consideração as etapas de desenvolvimento que já foram concluídas, deixando de fora grande parte do seu processo de aprendizagem. Desenvolveu, então, uma nova abordagem que procurava abarcar as aprendizagens que as crianças também eram capazes de realizar, desde que mediados por um adulto. 

papel preponderante. Transpondo para uma situação de formação "trata-se de recuperar, para uma classe de tarefas, a zona crítica onde o sujeito sabe tirar partido das ajudas que lhe são propostas, das representações que lhe são fornecidas, para resolver os problemas desta classe." (Pastré, 1994, p. 39, tradução livre). propõe a duplicação do conceito. Isto é, não existiriam uma mas duas zonas de desenvolvimento diferentes[1]. Uma primeira que retoma a ideia de desenvolvimento cognitivo mediado tal como proposto por Vygotski ; uma segunda que se refere à zona de desenvolvimento proximal dos “(...) motivos da actividade que singularizam desta vez o domínio subjectivo da experiência (...)" (p.172, tradução livre). Mesmo se Vygotski desde sempre preconizou a unidade dos processos afectivos e intelectuais (Vygotski, 1994 ; 1934/1997), para Clot, esta nova zona justifica-se já que uma nova atribuição de sentido à actividade pode ser suficiente para uma implicação diferente na acção. Clot (1999) exemplifica esta situação recorrendo a um estudo realizado em contexto real (Kugler, 1996 in Clot, 1999) sobre um conjunto de sessões, destinadas a alunos do equivalente ao $8^{\circ}$ ano português, que tinha como objectivo ensinar a nadar. Com efeito, estas sessões - dezoito no total só passaram a ser frequentadas com sucesso quando, depois de um ano de experiência, deixaram de ser de frequência obrigatória para passar a ser opcional. Mantinha-se, no entanto, como exigência a realização, por todos os alunos, das provas que garantiam que eles sabiam nadar de acordo com um conjunto de critérios previamente definidos: "Os que sabem nadar e que podem satisfazer as provas previstas pelo responsável terão a possibilidade imediata de aceder aos desportos opcionais valorizados pela maioria dos alunos." (p. 164, tradução livre). Assim, em vez de perceberem estas sessões como algo que os impedia de praticarem os seus desportos favoritos, os alunos passaram a frequentar estas sessões com o objectivo de adquirirem as competências identificadas o mais rapidamente possível para poderem passar para a prática do futebol ou basquetebol. Isto significa que a mesma actividade - aprender a nadar - foi sujeita a uma mudança de sentido e foi esta mudança que permitiu que pudesse passar a ser realizada com sucesso.

Se pretendermos que uma acção de formação profissional seja, então, uma situação de aprendizagem que possibilite o desenvolvimento dos adultos que a frequentam, para além de ter que favorecer a aprendizagem dos "verdadeiros " conceitos numa lógica de antecipação face àquilo que já é detido pelos sujeitos, tem também de garantir todo um conjunto de condições, tal como preconizado por Vygotski. Assim, como repetidamente o temos vindo a dizer, a formação tem de se constituir como uma situação formal de mediação social, sendo que, pelo uso da linguagem, se possibilita a apropriação das ferramentas e signos que permitem a aç̧ão sobre o objecto e a regulação de si próprio.

A nossa proposta neste trabalho vai no sentido de se utilizar o quadro referencial que acabámos de brevemente apresentar para a leitura de uma situação de formação profissional contínua dirigida a adultos profissionais da pesca.

Começaremos por procurar verificar se as condições para a aprendizagem propostas por Vygotski estavam reunidas e levantaremos algumas questões que resultam da confrontação com o real que uma situação destas sempre exige. 


\section{Uma acção de formação no mundo da pesca : da aprendizagem formal à utilização dos conceitos no dia-a-dia}

31 Esta investigação, conduzida num centro de formação profissional certificado para o sector das pescas, dedicou-se ao estudo de um curso de formação que permitia a aquisição da categoria de "contramestre pescador" (Santos, 2004).

Destacando-se de outras actividades profissionais, iniciar ou progredir uma actividade no sector das pescas exige a frequência de cursos de formação profissional, que garantam a obtenção das respectivas cédulas profissionais. Assim, neste caso concreto, a frequência deste curso habilitava ao reconhecimento formal de uma qualificação profissional enquanto contramestre pescador. Genericamente, pode-se dizer de um contramestre pescador que se não é o que, a bordo, assume as mais importantes decisões, ele deve, pelo menos, assegurar que as decisões tomadas sejam bem executadas. Deve ser o melhor de todos os pescadores, deve coordenar todas as tarefas mas deve ter também plena consciência do que acaba por exigir aos outros pescadores.

Este curso, com a duração de 380 horas, foi frequentado por 15 formandos, do sexo masculino, com idades compreendidas entre os 19 e os 49 anos, todos no activo e com uma experiência profissional na pesca.

Cinco destes formandos eram proprietários de embarcações e dois destes exerciam a bordo a função de mestre - tinham, portanto, todo o interesse em regularizar a sua situação, o que os obrigava a obter o certificado de contramestre pescador para, posteriormente, obter a carta de mestre.

Para além destes cinco proprietários, dois formandos já estavam a exercer a função de contramestre pelo que também tinham vantagem em regularizar a sua situação.

Estas informações, recolhidas em situação de entrevista individual, permitem compreender que se os principais motivos que conduziram estes trabalhadores à formação eram da ordem da progressão na carreira da pesca, em muitos casos era, também, da ordem da legalização de situações irregulares tendo em vista as normas definidas para a profissão.

Quanto ao curso propriamente dito, podemos dizer que é o próprio centro de formação que define o plano curricular onde identifica os domínios, conteúdos programáticos e distribuição de carga horária. Assim, a formação foi organizada em módulos, articulados entre momentos teóricos e práticos, sendo que os formadores eram solicitados em função da adequação da sua experiência à especificidade dos ensinamentos previstos : para as componentes práticas previstas em algumas unidades programáticas foram solicitados os formadores que possuem uma qualificação que resulta, entre outros, de uma vida de experiência no mar (em articulação com a necessária qualificação como formador) ; para as componentes de cariz mais teórico, optaram por formadores com uma formação escolar superior conciliando, se possível, com conhecimentos e experiência da vida no mar (muitas vezes relacionadas com a marinha comercial).

Os momentos de formação teórica eram essencialmente conduzidos segundo os princípios da transmissão, organizando-se os conhecimentos de forma hierárquica: partia-se da definição do conceito central para explicar as redes de relações que se 
estabelecem com outros conceitos e forma como se organizam, numa lógica que claramente respeita a aprendizagem dos "verdadeiros » conceitos.

Nos momentos práticos, o princípio era o de aplicação dos ensinamentos teóricos a situações não-espontâneas mas próximas da actividade real, realizando-se exercícios quer do tipo papel e lápis, quer praticando em simuladores de auxílio à deteç̧ão ou à navegação. Garantiria-se assim, o processo descendente que leva a que um conceito científico, mais abstracto num primeiro momento, possa, progressivamente, se ir concretizando e aplicando em diversas situações.

É claro que também havia espaço para o confronto com a forma como habitualmente as aç̧ões eram conduzidas na vida real. Os conceitos espontâneos que detinham eram, então, traduzidos por palavras, tornados conscientes, integrados numa rede de relações e autonomizados face a outros conceitos para que também estes tivessem oportunidade de evoluir desta vez de forma ascendente, no sentido da generalização e abstracção.

O cuidado na procura e selecção dos formadores enquanto interlocutores privilegiados de um determinado conjunto de conceitos (em função da "arte de pesca», da experiência que detém, da formação que tiveram) e uma prévia organização do conjunto de conceitos, respectivas redes de relações e hierarquias, considerados fundamentais para um futuro contramestre pescador, foram princípios observados nesta acção que parecem garantir as bases para uma aprendizagem geradora de desenvolvimento.

\subsection{Aprender a trabalhar com as novas tecnologias}

Para além dos motivos que os levaram à formação, os participantes esperavam também a possibilidade de melhor compreender as potencialidades oferecidas pelas novas aparelhagens - e, muito particularmente, eles procuravam adquirir a capacidade de utilização dos instrumentos que recorrem às novas tecnologias e foram concebidos de forma a os ajudar nas actividades de navegação e de detecção do pescado. Neste sentido, eles são unânimes em dizer que esta é a via da pesca do futuro, que permitirá uma outra eficácia, uma melhor produtividade e uma nova competitividade - e quando falam de competitividade, eles situam-se colectivamente face ao mercado espanhol que, efectivamente, dispõe de uma frota de pesca muito melhor equipada no plano das embarcações e dos equipamentos.

Dada importância da detecção do peixe (Figura 1) na actividade de um contramestre pescador e o interesse manifestado pelos formandos no desenvolvimento dos seus conhecimentos na utilização das ferramentas informatizadas, privilegiamos os momentos formativos que se dedicaram à explicação da forma de funcionamento e utilização de uma sonda (Figura 2). 
Figura 1 : Representação pictórica da utilização de uma sonda na pesca e Figura 2 : Exemplo de uma sonda a cores ção de uma sonda na pesca

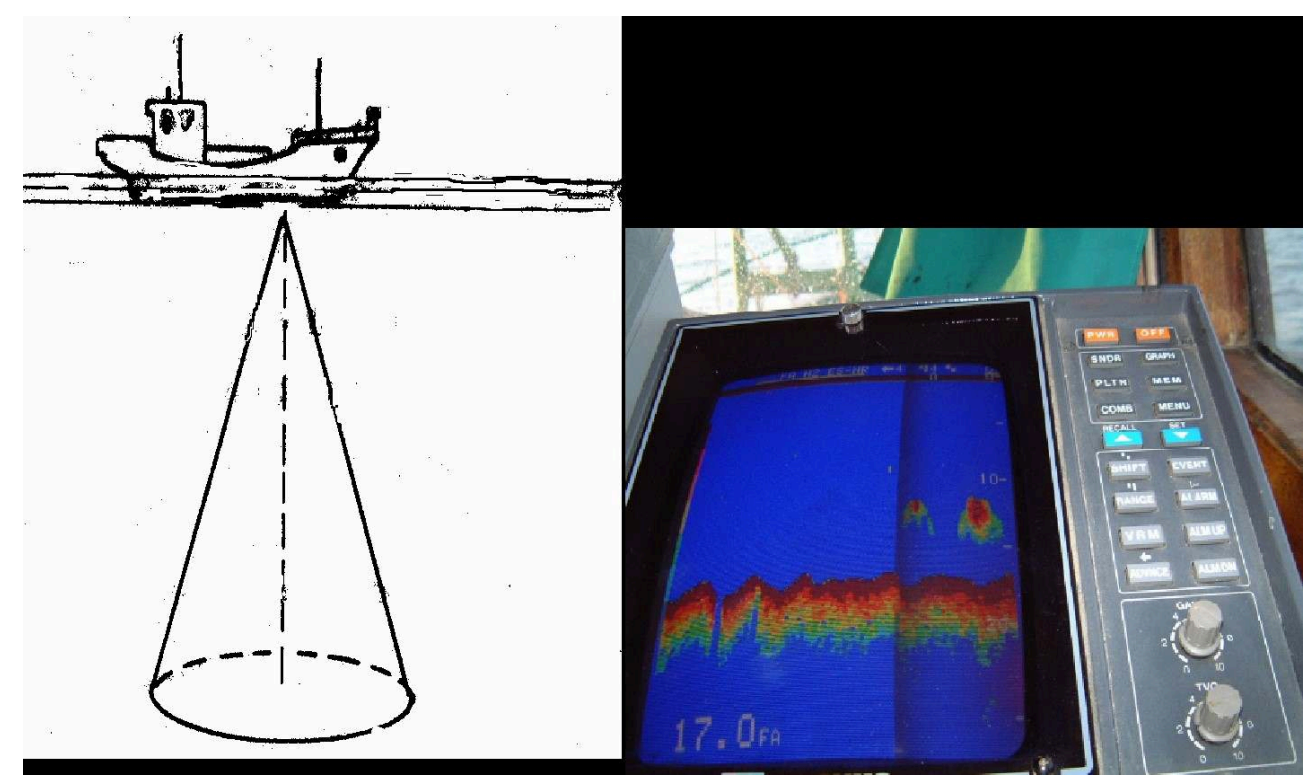

Com efeito, o funcionamento da sonda depende dos princípios da acústica, tem em conta a velocidade de propagação do som na água do mar e transmite, na imagem do écran, o resultado de diferentes tipos de ecos provocados assim que alcançam um determinado objecto (peixe, reverberações[2], características dos diferentes tipos de fundos).

A formação teórica consistiu, então, na apresentação e explicação do conjunto de conceitos considerados necessários afim de permitir a análise correcta dos diferentes tipos de ecos: transdutor, feixes sonoros, discriminação horizontal e vertical, eco, grandeza do eco, ruído-interferências e reverberações.

46 Nos momentos práticos, o formador procurou garantir a aquisição de um melhor domínio da lógica subjacente ao funcionamento da sonda: com este objectivo, apresentava e explicava num modelo relativamente recente mas similar ao que já existia em algumas das embarcações, o conjunto de comandos, o seu modo de utilização e as vantagens que oferecem para uma melhor leitura da imagem do écran. Nestes momentos, os formandos tinham a oportunidade de experimentar a utilização dos comandos através da realização de alguns exercícios que simulam situações prováveis de ocorrer numa sessão de pesca. A necessidade da articulação entre os conceitos teóricos e a utilização prática da sonda fazia todo o sentido para o formador já que alguns dos seus parâmetros podem (devem) ser ajustados em função das condições em que se pesca. Esta manipulação permite uma melhor leitura da imagem do écran da sonda, dando indicações mais precisas sobre a existência de peixe ou do tipo de fundo em que se está a navegar. Mesmo não sendo um processo completamente consciente e intencional por parte do formador, o que ele estava a favorecer era a possibilidade de um desenvolvimento dos conceitos nas duas direcções : do abstracto para o concreto e do particular para o geral.

Sublinhamos, no entanto, que a maioria dos participantes da acção de formação utilizavam regularmente uma sonda - mesmo se o equipamento de que dispunham não correspondesse necessariamente à versão utilizada no centro de formação. 

elementares, de uma forma global pode-se dizer que os quinze formandos foram capazes de identificar correctamente as situações e fazer as regulações previstas pelo exercício - apesar de, em muitos casos, terem conseguido graças à ajuda do formador que conduzia o exercício de simulação. Isto parece querer significar que os conceitos apresentados ou já estavam dominados ou se situavam na zona de desenvolvimento proximal destes formandos.

(a) preciso, permite recuperar uma situação que não fo identificada correctamente pela maioria dos formandos - a saber, os exercícios que se desenrolavam numa conjuntura de "dente de serra", tipo de registo que resulta da agitação marítima (Figura 3).

Figura 3 : Exemplo de um registo tipo “ dentes de serra »
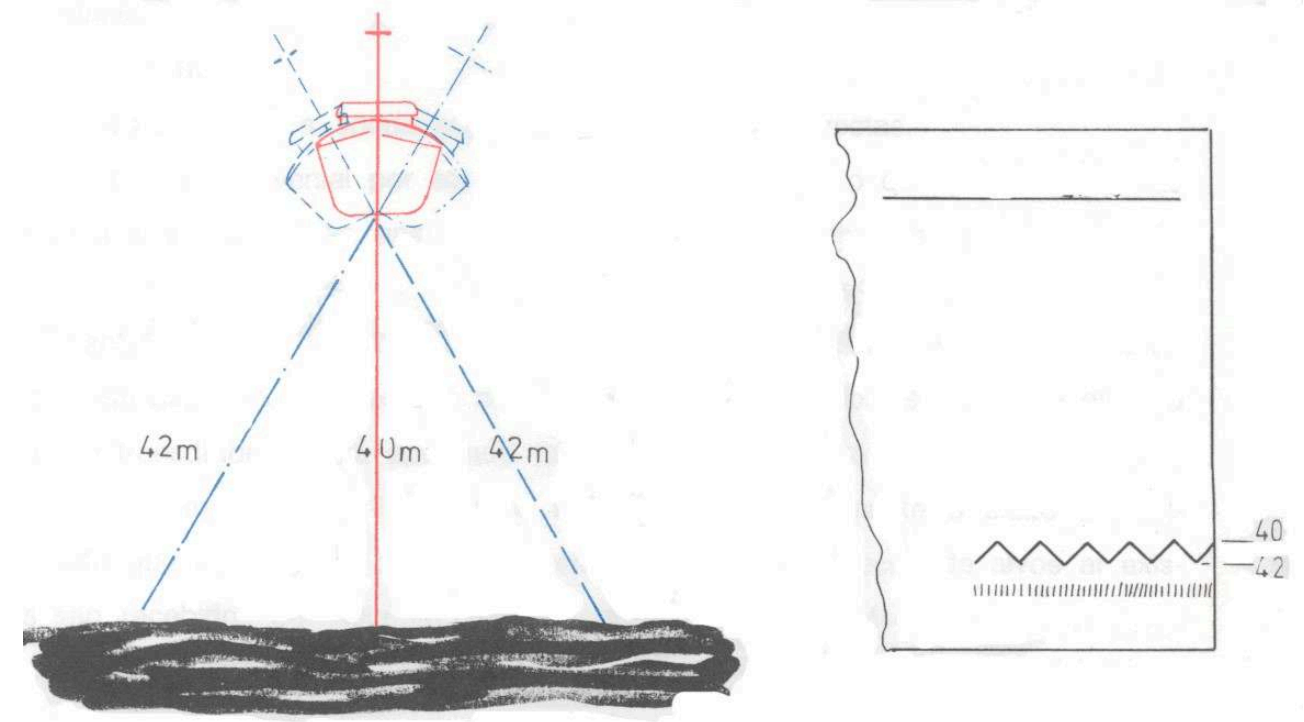
imagem da sonda), mas, sobretudo, uma estranheza face ao carácter artificial do exercício apresentado (figura 4). Na vida real, com efeito, nunca se passa de uma situação em que o mar está calmo e a fazer um registo de um fundo sem irregularidades (ver na figura 4 o registo relativo ao fundo antes da linha vertical vermelha), para uma situação em que se registam diferenças de aproximadamente $3 \mathrm{~m}$ de profundidade (ver na figura 4 o registo relativo ao fundo após a linha vertical vermelha) correspondendo a uma forte agitação marítima. No mar a situação evolui de forma progressiva, concedendo a oportunidade aos pescadores de se aperceberem que o novo tipo de registo só poderia ser resultante da alteração do estado do mar.

Figura 4 : Representação gráfica do exercício realizado no momento da avaliação

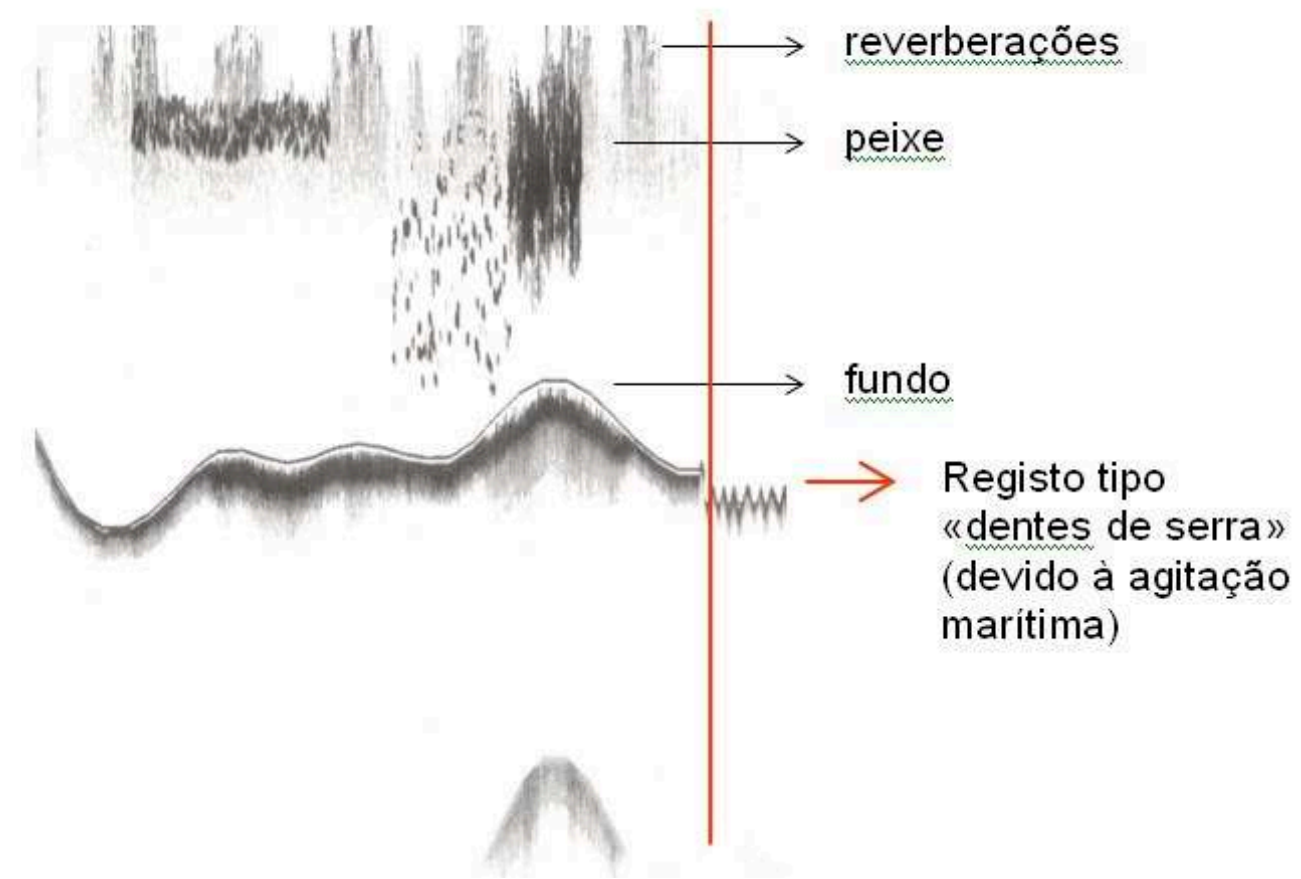

Mas talvez o aspecto mais interessante a propósito da realização deste exercício na sonda, tenha sido encontrar um discurso profundamente contraditório quando, após a simulação, se questionou sobre a importância dos novos conhecimentos disponibilizados. Apesar de salientarem a importância da evolução da pesca a partir do recurso a novas tecnologias (como a sonda), desvalorizavam as oportunidades criadas na formação para a aprendizagem de uma utilização " completa " da sonda porque consideravam que no real não são necessários determinados conhecimentos que foram ensinados ou então justificavam o seu interesse apenas para " artes de pesca » que não a sua.

Aliás, constatámos que a importância atribuída aos equipamentos e a sua generalização no mundo de pesca não é acompanhada pela sua utilização para além de determinadas funções. Com efeito, foram várias as verbalizações que registámos em que mestres, contramestres e pescadores referem que no dia-adia, praticamente só se liga e desliga a sonda (Figura 5). Não haveria, portanto, necessidade de fazer regulações nos comandos porque os parâmetros foram todos previamente introduzidos e os contramestres estariam em condições de fazer uma leitura e interpretação da imagem que lhes surge. 
Formando 2: “(...) e é por isso que a gente geralmente deixa sempre no mesmo ganho, está memorizada para aquilo e a gente não faz alteração. Geralmente é sempre assim."

Formando 5: "Não, não mexe muito. Não, não mexe muito, aquilo está controlado. Está posto da maneira que ele [mestre] quer regulado como ele quer,... ele praticamente mexe em 3-4 botões sempre, quase sempre, não mexe mais."

Formando 13 :"(...) na minha não, na minha só ligo, ligo, a gente marca o fundo mais nada!

Figura 5 : Identificação dos principais comandos de uma sonda, com indicação da frequência de utilização

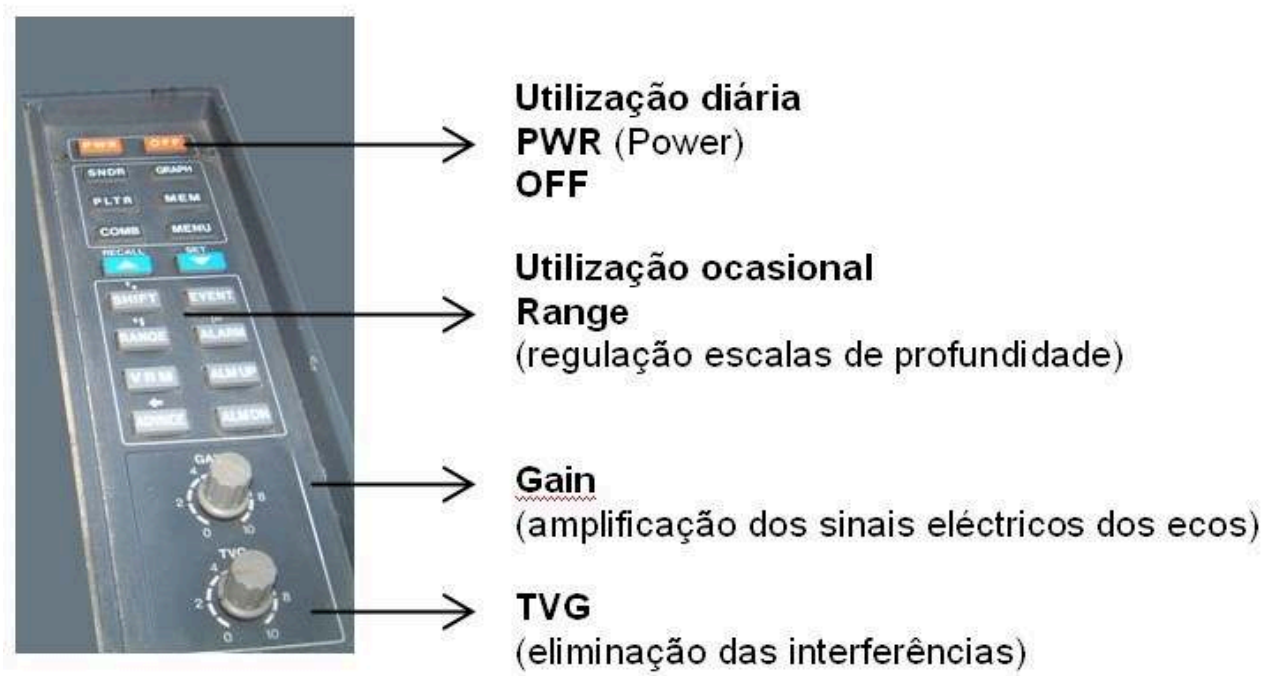

Poderíamos justificar esta situação pela ausência de uma análise do trabalho enquanto instrumento ao serviço da concepção desta acção de formação (Teiger, 1994), sendo a distância em relação à prática de todos os dias, a responsável pelo afastamento da formação, especialmente no que diz respeito à possibilidade de se conhecerem novas potencialidades da sonda. Poderíamos dizer, também, que ainda não houve génese instrumental [3] (Rabardel, 1995) porque ainda não tiveram oportunidade para se apropriar deste artefacto.

Contudo, mesmo se uma e outra nos parecem ser razões que contribuem, de alguma forma, para explicar a situação, não nos parecem suficientes para compreender a ambiguidade do discurso dos formandos entre a vontade de conhecer mais para pescarem mais e o achar que o que conhecem é amplamente suficiente para a sua " arte de pesca ».

Com efeito, apesar de no curso de formação se estar a trabalhar em simulação, o artefacto utilizado foi uma sonda verdadeira, pelo que a necessidade de tradução, dos esquemas de utilização, da formação para a vida profissional é, assim, facilitada ; para além disso, os formandos reconhecem a utilização diária deste tipo de instrumentos a bordo das embarcações - são, portanto, pertinentes para a actividade de pesca. O que de alguma forma parece garantir, de acordo com o que Clot (1999) acaba por sugerir, a possibilidade desta acção se encontrar na zona de desenvolvimento proximal dos motivos que conduziram os pescadores à formação. 
59 Por outro lado, a questão não parece ser a não utilização do artefacto em si (muitos dos formandos recorrem à sonda, diariamente, em contexto real e todos tiveram hipótese de a experimentar na formação e de conhecer a sua lógica de funcionamento), mas a utilização para além das funções consideradas mais básicas.

60 A ideia que resulta, verbalizada pelos formandos e formadores, é que não se mexe nos parâmetros introduzidos porque a sonda já está regulada, porque já sabem ler a imagem, porque os vendedores dos novos aparelhos, ainda mais sofisticados, sugerem que se evite a utilização dos comandos mais complexos para evitar avarias.

61 Mas, provavelmente, mais importante do que todas estas justificações, seja a que acabam por identificar quando se referem ao medo de perderem os conhecimentos que detêm aquela imagem já aprenderam a interpretar mas não podem garantir isso se mexerem nos comandos e não souberem voltar a pôr como estava. Os participantes alegam que entrando demasiado nos detalhes destas novas tecnologias, arriscam-se a perder o domínio das aparelhagens que utilizam no momento ou, pelo menos, de misturar os registos e, consequentemente, deixar de saber pescar. Isto numa conjuntura em que os seus saberes tradicionais se têm mostrados eficazes.

62 É preciso, também, sublinhar que este sentimento profundamente contraditório dos formandos é reforçado pelo facto de as políticas europeias para o sector das pescas delimitarem cada vez mais as quantidades e espécies de peixes que podem ser capturados : as perspectivas sobre o futuro da pesca são, assim, paradoxais, exigindo a aquisição de competências técnicas cada vez mais complexas para uma actividade cada vez mais limitada, restrita e controlado como nunca o foi antes - uma actividade para a qual as novas competências estão longe de ser indispensáveis. Se retomarmos Clot (1999) percebemos mais facilmente como esta actividade pode conter em si, em diferentes momentos, diferentes motivos o mesmo acto de pescar pode conduzir, então, a actividades muito distintas.

\section{Zona de desenvolvimento proximal e o medo de aprender em formação}

\subsection{Vygotski e a formação profissional}

Apesar de Vygotski não se ter debruçado especificamente sobre a questão da formação contínua de adultos, podemos, a partir da sua teoria geral sobre a aprendizagem, fazer sobressair alguns aspectos que para o nosso objecto merecem particular atenção.

Desde logo, a questão já referida sobre a possibilidade de existir um desenvolvimento ao longo de toda a vida : Vygotski não considera a adolescência como o término de um processo, mas antes como um momento que se caracteriza pela forma como passamos a utilizar a linguagem. Isto porque, nesta fase, a linguagem adquire, finalmente, uma certa funcionalidade, que, em conjunto com um meio desafiador e que proporcione experiências relevantes, nos leva ao pensamento conceptual.

Contudo, convém lembrar que, mesmo em adultos, não utilizamos só o pensamento conceptual (esta forma superior, especificamente humana): continuamos a actuar sobre os objectos, muitas vezes sem termos consciência do modo como o estamos a fazer. Aliás, para Vygotski muitos dos “saberes-fazer" técnicos mobilizados na actividade de trabalho (e não só) não promovem o desenvolvimento : são passíveis de 
aprendizagem, mas, como são associados à “inteligência prática ", correspondem a formas de pensamento menos evoluídas.

É um facto que determinados trabalhadores realizam as suas actividades de trabalho de uma forma quase automática. Aprenderam no quotidiano, a observar, a ensaiar - sabem que realizam mas não estão conscientes de todos os aspectos relativos à forma como realizam.

Uma acção de formação contínua que visasse o desenvolvimento destes trabalhadores teria, então, de possibilitar a tomada de consciência do sistema simbólico utilizado na actividade de trabalho - tornar o trabalho um objecto da consciência (Clot, 1999).

Assim, se Vygotski estudasse esta questão, provavelmente proporia uma reflexão mediada sobre a actividade de trabalho, a possibilidade de traduzir por palavras estes “saberes-fazer técnicos». Criaria uma situação onde fosse possível explicitar verbalmente um conflito gerado dentro da zona de desenvolvimento proximal esperando que o debate suscitado fosse resolvido e interiorizado pelos trabalhadores (Schneuwly, 1994).

69 Nestas condições, unindo uma forma de pensamento não verbal à linguagem, passaríamos para o domínio do pensamento verbal, conceptual, reflectido, consciente e, então, promotor de desenvolvimento "integral e harmonioso". E, assumindo este pontodevista,parecequeoquefaltaaos" saberes-fazertécnicos » e especializados não advém da sua natureza, do facto de terem de ser diferentes, mas antes a sua passagem pela esfera da linguagem.

70 Talvez possamos, então, sugerir que a principal consequência para a formação se situe ao nível da prioridade que deve ser concedida à linguagem e ao discurso dos formandos/trabalhadores. Se a formação não proporcionar a possibilidade de " pôr por palavras " a actividade quotidiana, a resolução dos conflitos gerados e a interiorização do resultado destes debates, então não vai permitir que haja desenvolvimento. Em contrapartida, quando há este espaço, independentemente da idade ou da forma de pensar dominante, a formação pode intervir num processo, pode interferir num percurso histórico.

71 Assim, uma via possível para a concepção de acções de formação que visam o desenvolvimento deveria reunir as seguintes condições: promover situações de aprendizagem em que a mediação do outro, dos instrumentos e signos próprios actuem na zona de desenvolvimento proximal, de forma a que os conflitos aí gerados sejam verbalizados e os seus resultados interiorizados. Esta seria uma via possível para que os conceitos científicos adquiridos se concretizassem e os conceitos espontâneos se elevassem, generalizassem e sistematizassem.

\subsection{Medo de aprender e o estatuto dos saberes}

72 Mas o que não questionamos até aqui foi o estatuto dos saberes que são ensinados. No caso que apresentámos dissemos, por diversas vezes, que a escolha dos conteúdos dependia exclusivamente do centro de formação e dos respectivos formadores. Eram eles que definiam os conceitos, estabeleciam as relações, hierarquizavam-nos. Os novos saberes que eram ensinados eram considerados como os essenciais para o exercício profissional e para a preparação destes pescadores para uma pesca tecnologicamente mais evoluída e competitiva. 
73 Todavia a reacção dos formandos no decurso do processo formativo demonstrou que mesmo quando se actua na zona de desenvolvimento proximal (cognitiva e dos motivos) e se está em condições de aprender, podem surgir outros factores que vão condicionar todo o processo. Foi isto que encontramos e que identificamos como o medo de aprender.

74 No discurso dos participantes era evidente o medo de perder o domínio sobre os saberes anteriores, associado ao medo de uma pesca cada vez menos frutuosa. E, este medo era mais forte do que o desejo de aprender.

75 Assim, a possibilidade de dominar a linguagem destas novas tecnologias foi ponderada face ao medo de perder os conhecimentos e procedimentos que utilizavam, e que, até ao momento, se tinham mostrado adequados para a resolução dos seus problemas : se não alterarem os parâmetros da sonda é garantido que sabem interpretar a imagem e tomar as melhores decisões que anos de prática ajudaram a consolidar. Situação que é reforçada, ainda, pelos vendedores de novos aparelhos que sugerem o bloqueio de certos comandos.

76 Esta ponderação faz-nos questionar sobre a possibilidade de existência de uma terceira zona de desenvolvimento proximal : a que resulta de uma análise e avaliação prudentes sobre a decisão de aprender algo novo face à eficácia “ apesar de tudo » que é preciso manter no confronto com o real.

77 Admitimos que há medida que a formação foi avançando os formandos foram-lhe atribuindo novos sentidos. Poderíamos considerar até que, em determinada altura, as aprendizagens previstas na formação já não se encontravam a actuar dentro da zona de desenvolvimento proximal dos motivos para estes formandos. No entanto, a existência de um conflito, gerado quando iniciaram o módulo que implicava a utilização das novas ferramentas informáticas $\left.{ }^{4}\right]$, leva-nos antes a questionar se o medo de aprender não corresponderá à impossibilidade de resolver, no seio da formação, esta contradição aprender algo novo versus manter os saberes que detêm acabando por impedir a sua resolução e interiorização.

78 Assim, quanto a nós, estas situações comprovam o interesse de se conduzir um debate que permita aos formandos explicitarem, analisarem e confrontarem as vantagens e os limites da opção por novos instrumentos ou pelo desenvolvimento das potencialidades dos que já possuem - isto é, construir um espaço de intervenção dentro desta terceira zona de desenvolvimento. Na ausência deste debate, a transmissão dos novos conhecimentos e novos esquemas de acção pode ser vivido com medo de perderem a possibilidade de lidar com as situações para as quais os instrumentos até então utilizados se mostravam úteis face aos resultados da acção.

79 Não ponderar o estatuto destes saberes em formação - não intervindo dentro desta zona de desenvolvimento significa, quanto a nós, afirmar uma concepção absoluta dos novos saberes : os novos saberes são tidos como fontes de progresso, nunca se chegando sequer a questionar a pertinência dos saberes já existentes. 


\section{BIBLIOGRAFIA}

Bronckart, J.-P. (1985). Vygotsky, une oeuvre en devenir. In B. Schneuwly et J.-P. Bronckart (Dir.). Vygotski aujourd'hui. (pp. 7-21). Neuchâtel : Delachaux \& Niestlé.

Clot, Y. (1995). Le travail sans l'homme? Pour une psychologie des milieux de travail et de vie. Paris : Éditions la Découverte.

Clot, Y. (1999). La fonction psychologique du travail. Paris : PUF. Desforges, Y. (2001). Postface à Du mode d'existence des objets techni-

ques (pp. 268-331). Mayenne : Aubier.

Pastré, P. (1994). Variations sur le développement des adultes et leurs

représentations. Education Permanente, nº 119, 2, 33-63.

Rabardel, P. (1995). Les hommes et les technologies : approche cognitive des instruments contemporains. Paris : Armand Colin.

Rochex, J.-Y. (1997). L'oeuvre de Vygotski : fondements pour une psychologie historico-culturelle. Revue Française de Pédagogie, 120, juillet-août-septembre, 105-147.

Santos, M. (2004). O projecto de uma Sociedade do Conhecimento : de Lev Vygotski a práticas efectivas de formação contínua em Portugal. Dissertação tendo em vista a obtenção do grau de Doutor em Psicologia. Porto : Faculdade de Psicologia e Ciências da Educação da Universidade do Porto.

Schneuwly, B. (1994). Contradiction and development : Vygotski and Paedology. European Journal of Psychology of Education. Vol IX, nº4, 281-291.

Teiger, C. (1994). La formation à l'analyse ergonomique du travail, outil de changement des représentations pour changer le travail. Actes des Journées de Bordeaux sur la Pratique de l'Ergonomie. Bordeaux.

Vygotski, L. (1994). Problématique de l'arriération mentale. In K. Barisnikov et G. Petitpierre (Dir.). Défectologie et déficience mentale_ Vygotsky. (195-236). Lausanne : Delachaux \& Niestlé.

Vygotski, L. (1997). Pensée \& langage. (3e édition) (F. Séve, trad.). Paris : La Dispute. (Edição original, 1934).

Vygotski, L. (1998). A formação social da mente. (6ª edição) (J. Neto, L. Barreto, \& S. Afeche, trad.). São Paulo : Martins Fontes. (Edição original, 1931).

\section{NOTAS}

1. Aliás, Clot (1995) prefere chamá-las de «zonas de desenvolvimento potencial» para garantir um enfoque superior na potencialidade do que na proximidade a mediação do outro permite desenvolver o que está em potencial, o que não tem que significar necessariamente que seja próximo daquilo que já está desenvolvido.

2. Provocadas pelo movimento da hélice, bolhas de ar, plancton.

3. Se assumirmos, com Rabardel (1995) que é necessário utilizar os artefactos e mobilizar esquemas para adquirirmos um instrumento, estamos em condições para perceber que o 
processo de génese instrumental se refere precisamente ao modo como os sujeitos desenvolvem os instrumentos para si próprios.

4. Verbalizado apenas nas entrevistas que conduzimos.

\section{RESUMOS}

Este artigo procura reflectir sobre uma situação de aprendizagem num curso de formação para pescadores. Após apresentar de forma breve alguns conceitos de Vygotski, mostraremos como em determinadas situações, para que a aprendizagem possa ser efectiva, é preciso saber não só identificar os “verdadeiros » conceitos e conhecer a “ zona » onde estamos a intervir por forma a permitir o desenvolvimento cognitivo e dos motivos mas também o que é que se passa no confronto desta aprendizagem quando se depara com o real. No confronto com a "vida real », o medo de se perder os conhecimentos que se detêm e que se mostram eficazes "apesar de tudo " pode ser uma variável não desprezível em formação e que deve ser debatida para que os novos saberes não assumam um estatuto absoluto e se tornem apenas uma imposição.

Este artículo procura reflexionar sobre una situación de aprendizaje en un cursillo de formación para pescadores. Tras presentar de forma breve algunos conceptos de Vygotski, mostraremos como en determinadas situaciones, para que el aprendizaje pueda ser efectivo, es necesario saber no sólo identificar los "verdaderos" conceptos y conocer la “zona " donde estamos interviniendo para permitir el desarrollo cognitivo y de los motivos como también lo que ocurre en la confrontación de este aprendizaje cuando se depara con lo real. En la confrontación con la "vida real», el miedo de que se pierdan los conocimientos que se poseen y que se muestran eficaces " a pesar de todo" puede ser una variable no despreciable en formación y que debe de ser debatida para que las nuevas sabidurías no asuman un estatuto absoluto y se conviertan a penas en una imposición.

Cet article veut réfléchir à propos d'une situation d'apprentissage intégrée dans un cours de formation de pêcheurs. Après avoir présenté de façon synthétique quelques concepts de Vygotski, nous montrerons comment, dans le cadre de certaines situations, pour que l'apprentissage puisse être effectif, il est nécessaire non seulement d'identifier les "vrais " concepts et connaître la “zone » où nous intervenons, de façon à permettre le développement cognitif e des motifs, mais également ce qui se passe dans la confrontation de cet apprentissage avec le réel. Dans cette confrontation, la peur de perdre les connaissances détenues et qui se montrent efficaces malgré tout, peut être une variable à ne pas négliger en cours de formation et qui doit être débattue pour que les nouveaux savoirs n'assument pas un statut absolu et soient imposés.

This article presents a reflection on a learning situation in a training course for fishermen. After briefly presenting some of Vygostki's concepts, we will show how, in some situations, in order to achieve effective learning we need to know not only how to identify the "true" concepts and to know the "zone" in which we are intervening (to allow cognitive and motivational development), but also what happens in the confrontation of this learning with the real. In the confrontation with "real life", the fear of losing the detained knowledge (that proves to be effective, "in spite of everything"), can be a variable that we should not neglect with regard to training. On the 
contrary, that variable should be debated in order to prevent the new knowledge from assuming an absolute statute, and becoming a mere imposition.

\section{ÍNDICE}

Palabras claves: zona de desarrollo proximal, formación profesional, miedo de aprender Keywords: zone of proximal development, professional training, fear of learning

Mots-clés: zone prochaine de développement, formation professionnelle, peur d'apprendre Palavras-chave: zona de desenvolvimento proximal, formação profissional, medo de aprender

\section{AUTORES}

\section{MARTA SANTOS}

Universidade do Porto - Faculdade de Psicologia e de Ciências da Educação Rua Dr. Manuel Pereira da Silva, 4200-392 Porto

marta@fpce.up.pt

\section{MARIANNE LACOMBLEZ}

Universidade do Porto - Faculdade de Psicologia e de Ciências da Educação Rua Dr. Manuel Pereira da Silva, 4200-392 Porto

lacomb@fpce.up.pt 